\title{
Design and psychometric evaluation of the fathers' fear of childbirth scale: a mixed method study
}

\author{
Seyedeh Fatemeh Ghaffari ${ }^{1} \mathbb{B}$, Hamid Sharif $\mathrm{Nia}^{2} \mathbb{B}$, Forouzan Elyasi ${ }^{3} \mathbb{D}$, Zohreh Shahhosseini ${ }^{4 *}$ (D) and \\ Zohre Mohammadpoorsaravimozafar ${ }^{1}$ (i)
}

\begin{abstract}
Background: Fear of childbirth is reported in 13\% of fathers, and it may have adverse consequences for the fathers' health as well as their families. To reduce the fear of childbirth in the expectant fathers, an appropriate screening tool is needed. Due to the lack of a valid and reliable questionnaire to measure fathers' fear of childbirth, this study was conducted to develop the Fathers' Fear of Childbirth Scale and evaluate its psychometric properties.

Methods: This mixed method study was conducted in two phases. In the qualitative phase (or item generation), semi-structured interviews were conducted with 20 expectant fathers, and a literature review was performed to generate the Fathers' Fear of Childbirth Scale items pool. In the quantitative phase (or psychometric evaluation), reliability as well as face, content, and construct validity of this scale were evaluated. To establish construct validity, exploratory and confirmatory factor analyses were performed. Reliability was evaluated through internal consistency and composite reliability measures.

Results: The primary version of Fathers' Fear of Childbirth Scale contained 32 items, which were reduced to 17 items while establishing construct validity. Exploratory factor analysis extracted two factors, namely fear of childbirth process (12 items) and fear of hospital (5 items). These factors explained $50.82 \%$ of the total variance. Goodness of fit indices within the confirmatory factor analysis was acceptable. Internal consistency and composite reliability indices of all the factors were greater than 0.70 .

Conclusion: The Fathers' Fear of Childbirth Scale has a suitable validity and reliability for assessing fear of childbirth in fathers. It is a simple report instrument that can be easily implemented by health care professionals.
\end{abstract}

Keywords: Childbirth, Fathers, Fear, Tocophobia, Psychometric

\section{Background}

Pregnancy, childbirth, and parenting instigate different emotional responses in fathers, including fear of childbirth [1-3]. The fear of childbirth is defined as a negative perception starting in the antenatal period and mostly experienced during labor and delivery [4]. Some

\footnotetext{
* Correspondence: zshahhosseini@yahoo.com

${ }^{4}$ Sexual and Reproductive Health Research Center, Mazandaran University of Medical Sciences, Sari, Iran

Full list of author information is available at the end of the article
}

biopsychosocial factors may lead to the fear of childbirth in fathers including the interventions during labor and their side effects [5], damage to pregnant mother and her child [5, 6], painful labor and delivery [6, 7], inability to support the spouse [7], disrespectful behaviors by hospital staff [5, 8], and financial constraints [6].

In clinical practice, fear levels are commonly divided into low, moderate, severe, and phobic fear [9]. Some degree of fear of childbirth can be considered normal, but its exacerbation during pregnancy and childbirth is

(C) The Author(s). 2021, corrected publication 2021. Open Access This article is licensed under a Creative Commons Attribution 4.0 International License, which permits use, sharing, adaptation, distribution and reproduction in any medium or format, as long as you give appropriate credit to the original author(s) and the source, provide a link to the Creative Commons licence, and indicate if changes were made. The images or other third party material in this article are included in the article's Creative Commons licence, unless indicated otherwise in a credit line to the material. If material is not included in the article's Creative Commons licence and your intended use is not permitted by statutory regulation or exceeds the permitted use, you will need to obtain permission directly from the copyright holder. To view a copy of this licence, visit http://creativecommons.org/ licenses/by/4.0/. The Creative Commons Public Domain Dedication waiver (http://creativecommons.org/publicdomain/zero/1. 0/) applies to the data made available in this article, unless otherwise stated in a credit line to the data. 
undesirable $[10,11]$. According to the existing literature, severe fear of childbirth has been reported in 13\% of fathers and it may have poor consequences for the health of fathers as well as their families $[8,12]$. Some of those including cesarean delivery [13], mental and physical problems in the expectant fathers $[6,14]$, poor support from the pregnant mother [5], impairment of fatherpregnant mother/child relationship [15], and the unpleasant experience of childbirth [8]. Preparation for childbirth may help distressed expecting fathers to enjoy a more positive childbirth experience [15]. Therefore, fathers at risk of fear of childbirth must be identified and promptly supported by the appropriate services. Screening the expectant fathers experiencing fear of childbirth requires a valid instrument.

To the best of our knowledge, few studies have investigated fear of childbirth in fathers and only a limited number of validated instruments exist to identify this problem $[8,12]$. The 52 -item questionnaire designed by Ringler [16] and the 33-item Wijma Delivery Expectancy/Experience Questionnaire (W-DEQ) are two instruments administrated to identify fathers with fear of childbirth [15]. Although the original version of W-DEQ was designed to measure the fear of childbirth in women [17], Bergstrom et al. used this questionnaire for expectant fathers by excluding some items irrelevant for men such as some items about labor and delivery processes [18]. Some studies have used the Fear of Birth Scale (FOBS) to measure fear of childbirth in fathers $[12,19$, 20]. This scale was also initially introduced to measure the fear of childbirth in women, and there is no evidences about the validity and reliability of this scale for assessment of fathers' fear of childbirth [12].

It is stated that the content of any tool should be culturally appropriate for the target group for which they are intended [21]. As a valid and reliable tool is needed to investigate fathers' fear of childbirth, this study aimed to design and examine psychometric properties of the Fathers' Fear of Childbirth Scale (FFCS) In Iranian setting.

\section{Methods}

\section{Design and setting}

This methodological research was conducted in two phases between May 2019 and January 2020. A qualitative content analysis and item generation were performed in the first phase. The second phase involved a psychometric evaluation of the tool and the assessment of its validity and reliability.

This project was conducted in prenatal clinics of health care centers affiliated to Mazandaran University of Medical Sciences (MAZUMS), Sari, Iran. Sari, the capital of Mazandaran province- northern Iran, is the largest and most populous city in this area. In this city, public coverage includes primary health care. Expectant fathers, who attended in the prenatal visits with their spouses in second or third trimester of pregnancy, were employed.

\section{Qualitative phase (item generation)}

At first for designing the FFCS, semi-structured interviews with the expectant fathers was conducted. During interviews, fathers were held to explore their experiences related to fear of childbirth. Participants selected using purposeful sampling with maximum variation in terms of age, education, and occupation. The interviews lasted 60-90 min and were recorded by the researcher. All interviews were held in Persian and by the same interviewer (A Master of Science in Midwifery on the supervision of research team including a psychiatrist and a reproductive health specialist). Data saturation was reached after 20 interviews. After transcribing the interviews, they were analyzed through the conventional four-step content analysis approach. Accordingly, each interview was divided into meaningful units, which were condensed and coded. Then, the resulting codes were grouped into categories and subcategories [22]. Data was managed using the MAXQDA 10 software, and trustworthiness was ensured via Guba and Lincoln's criteria, including credibility, dependability, confirmability, and transferability [23].

Also, in this phase, a comprehensive search in the relevant databases such as: Scopus, Science Direct, Psych Info, PubMed, and Cochrane were conducted. Keywords and syntaxes were as follows: ["Fear" OR "Tocophobia"] AND ["Childbirth" OR "Delivery" OR "Parturition" OR "Birth"] AND ["Pregnancy" OR "Gestation"] AND ["Father" OR "Men" OR "Couple" OR "Paternal"] AND ["Related Factors" OR "Influence Factors" OR "Contributed Factors"] AND ["Psychometry" OR "Psychometric"] AND ["Scale" OR "Questionnaire" OR "Tool" OR "instrument"]. The literature review was carried out until saturation was reached for the items of the FFCS. Finally, based on the results of the interviews and literature review, an item pool was generated.

\section{Quantitative phase (psychometric evaluation)}

In the quantitative phase, reliability as well as face, content, and construct validity of the FFCS were established.

\section{Face validity}

The face validity of the FFCS was evaluated both qualitatively and quantitatively. For qualitative face validity, 10 expectant fathers were invited to comment on the difficulty, appropriateness, clarity, and essentiality of the items. The items were then modified based on their comments. For quantitative face validity, 20 expectant fathers were asked to rate the importance of each item 
on a 5-point scale ranging from 1 (Not important) to 5 (Very important). The impact score of each item was calculated by multiplying its importance score by the number of fathers who had rated it 4 or 5 . An impact score greater than 1.5 was considered appropriate [24].

\section{Content validity}

Content validity was also evaluated using both qualitative and quantitative methods. For qualitative content validity, 11 experts (i.e., two gynecologists, six reproductive health and midwifery specialists, and three psychiatrists) who were experienced in instrument development were asked to comment on the structure, wording, item allocation, and scoring of the FFCS items. The scale was amended based on their comments. Next, content validity ratio (CVR) and content validity index (CVI) of the primary version of the scale were evaluated. Accordingly, for CVR evaluation the expert group was asked to rate the essentiality of each FFCS item as being "Essential" (score of 1), "Useful but not essential" (score of 2), or "Not essential" (score of 3). Based on the Lawshe Table, items with CVR values less than 0.59 were excluded [25]. For CVI calculation, the same expert group was invited to rate the relevance of each item. Item CVI (ICVI) with values more than 0.79 were considered appropriate, between 0.79 and 0.70 were revised, and scores below 0.70 were considered unacceptable [24]. In addition, an average scale-level CVI (S-CVI/Ave) was evaluated. An S-CVI/Ave of greater than 0.80 was considered acceptable.

\section{Item analysis}

Prior to construct validity evaluation, 30 expectant fathers were asked to complete the FFCS. Their responses were used for internal consistency evaluation. Items with an inter-item correlation coefficient of less than 0.30 and greater than 0.80 were omitted.

\section{Construct validity}

Comrey and Lee (1992) offered a rough rating scale for adequate sample sizes in factor analysis as follows: $100=$ poor, $200=$ fair, $300=$ good, $500=$ very good, 1000 or more $=$ excellent [26]. Therefore, 433 eligible fathers were recruited to complete the 23-items FFCS and socio-demographic checklist for exploratory (200 fathers) and confirmatory factor analyses (233 fathers). The sociodemographic checklist included items on age, level of education, occupation, number of children, and having a wanted pregnancy. Convenience sampling was used to choose the participants from the health care centers affiliated to MAZUMS. Inclusion criteria were basic literacy, no history of hospitalization in psychiatric hospitals, and consent to participate in the study. Highrisk pregnancies, any history of a child with physical or mental abnormalities in the family, and chronic maternal illnesses that endanger the mother's life were exclusion criteria.

For exploratory factor analysis (EFA), sampling adequacy was assessed via the Kaiser-Meyer-Olkin and Bartlett tests. Then, the latent factors of the FFCS were extracted via the maximum-likelihood EFA with Promax rotation. The number of extractable factors was determined via parallel analysis. The minimum acceptable factor loading for the presence of an item in a factor was 0.3 , which was calculated using the equation below:

$C V=5.152 \div \sqrt{ }(\mathrm{n}-2)$. Based on the three-indicator rule, each factor had to have at least three items [27]. Items with communality values less than 0.2 were excluded [28].

Using confirmatory factor analysis (CFA), the extracted factor model was evaluated via maximum likelihood estimation by using the following model fit indices: incremental fit index (IFI), comparative fit index (CFI), adjusted goodness of fit index (AGFI), parsimony normed fit index (PNFI), parsimony comparative fit index (PCFI), root mean score error of approximation (RMSEA), and minimum discrepancy function divided by degrees of freedom (CMIN/DF).

\section{Normal distribution, outliers, and missing data}

Univariate normality was evaluated using skewness $( \pm 3)$ and kurtosis $( \pm 8)$. Multivariate outliers were assessed via the Mahalanobis D squared test $(P<0.001)$. Moreover, multivariate normality was assessed via Mardia coefficient of multivariate kurtosis $(<20)$ [23]. Missing data was assessed via multiple imputations, and it was replaced with the mean of participants' scores.

\section{Reliability}

Cronbach's alpha, McDonald's omega, and AIC were calculated to evaluate internal consistency [29]. An acceptable internal consistency involved a coefficient greater than 0.70 and an AIC between 0.20 and 0.40 [27]. The data was analyzed using SPSS-AMOS24 and SPSS R-menu 2.0 .

\section{Results}

\section{Item generation}

Analysis of the interviews resulted in the development of seven main categories that may lead to fear of childbirth in fathers. These categories included harm to the mother's health, lack of adequate care from the mother, harm to the child's health, interpersonal and relational factors, expenses, childbirth complications, lack of information about childbirth and its stages, and parenting role.

The review of literature resulted in six categories in terms of factors may lead to fear of childbirth in the expectant fathers including maternal factors (e.g., health and safety of the mother, mother's capability in 
childbirth, mother's pain, mother's fear, and maternal birth control), paternal factors (e.g., lack of information about childbirth, inability to support the spouse, and to be a good father), child-related factors (e.g., health and safety of the child, infant anomaly, childbirth injuries, and hospitalization in neonatal intensive care unit), health care providers factors (e.g., professional's competence and behavior), birth process factors (e.g., poor outcome of delivery and assisted delivery), and hospitalrelated factors (e.g., facilities and equipment).

Based on the results of the conducted interviews and the literature review, 61 items were generated. A further refinement of the items reduced the items number to 37 (Fig. 1). These 37 items were grouped into the following categories: fear of maternal-related factors (five items), fear of paternal-related factors (15 items), fear of childrelated factors (three items), fear of interpersonal and relational related factors (two items), fear of treatment staff-related factors (four items), fear of birth process- related factors (six items), and fear of hospital-related factors (two items).

\section{Face and content validity}

Three items were revised in the qualitative face validation stage and four items were revised in the quantitative face validation stage due to impact scores less than 1.5. As shown in Fig. 1 content validity resulted in the exclusion of five items due to CVR values less than 0.59. Based on CVI values, no item was deleted and the S-CVA/Ave of the FFCS with 32 remaining items was 0.85 .

\section{Item analysis}

Based on the internal consistency evaluation, nine items with inter-item correlation coefficients less than 0.30 were excluded (Fig. 1).

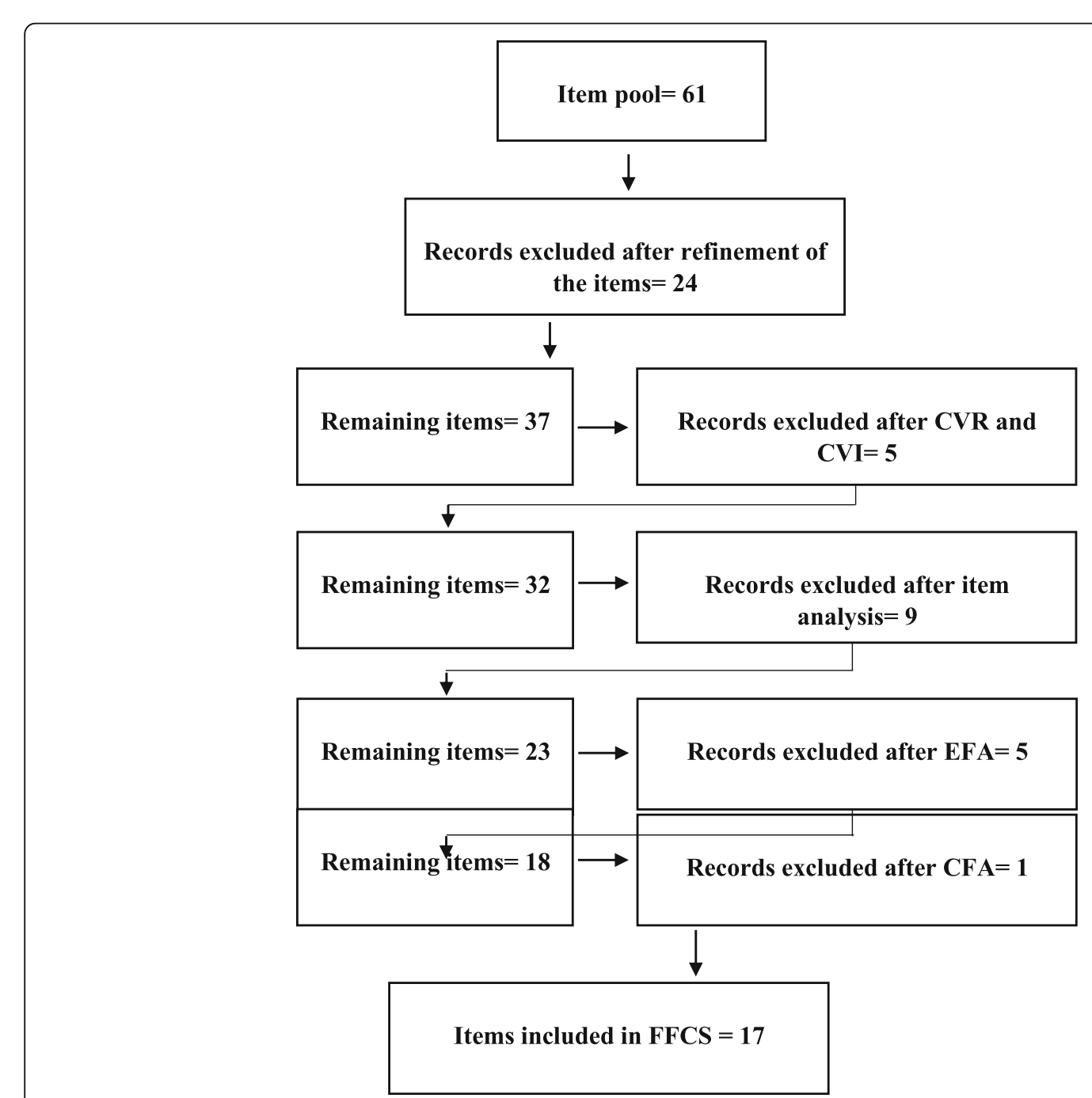

Fig. 1 Items selection process 


\section{Construct validity}

In total, 433 fathers completed the FFCS with 23 items for factor analysis. Their mean age was $30.22 \pm 2.74$ years, $60.53 \%$ of the fathers had a university degree, 98.3\% were employed, $42.81 \%$ had no children, and $38.90 \%$ had one child. In addition, $86 \%$ of the pregnancies were wanted.

A maximum likelihood EFA with Promax rotation was performed on the data obtained from 200 fathers. The Keiser-Meyer-Olkin test value was 0.91 and the Bartlett's test value was $2985.98(P<0.001)$. In this step, five items as a result of communality values less than 0.2 were deleted. A parallel analysis resulted in the extraction of two main factors: fear of childbirth process (12 items) and fear of hospital (6 items). The eigenvalues of these two factors were respectively 5.21 and 3.93, and they explained $50.82 \%$ of the total variance of the FFCS (Table 1).

The extracted factor structure was evaluated using CFA and the data obtained from 233 fathers. In the first-order CFA, after modifying the model and drawing the correlation between the measurement errors $e_{1}$ and $\mathrm{e}_{5}, \mathrm{e}_{1}$ and $\mathrm{e}_{9}, \mathrm{e}_{2}$ and $\mathrm{e}_{3}, \mathrm{e}_{2}$ and $\mathrm{e}_{6}, \mathrm{e}_{3}$ and $\mathrm{e}_{9}, \mathrm{e}_{7}$ and $\mathrm{e}_{11}$, $\mathrm{e}_{8}$ and $\mathrm{e}_{10}$, and $\mathrm{e}_{15}$ and $\mathrm{e}_{16}$, the Chi-squared test for goodness-of-fit was obtained as the first fitting index ( $\mathrm{x} 2$ $[\mathrm{df}=110, N=233]=287.67, p<0.001)$. To evaluate the fitting of the model, other indices were evaluated (IFI = 0.919, CFI $=0.918$, AGFI $=0.824$, PNFI $=0.707$, PCFI $=$ 0.742 , RMSEA $=0.083, \mathrm{CMIN} / \mathrm{DF}=2.615)$, which perfectly confirmed the final model (Table 2, Fig. 2). At the end of this stage, the items of FFCS reached to 17.

After the first-order CFA, a separate assessment of the factors of the fear of the childbirth in fathers and the correlation between its constructs was performed. The second CFA was conducted to confirm the general concept of "tocophobia". Figure 3 shows the structural model and the second order CFA of the FFCS with the standardized factor loading coefficients. The amount of factor loading obtained for FFCS was more than 0.5 for all the items, being significant at $p<0.001$. Internal consistencies of all the factors were greater than 0.70 , which confirmed the acceptable internal consistency of the factors (Table 3).

Table 1 Factors extracted from FFCS

\begin{tabular}{|c|c|c|c|c|c|}
\hline Factors & Items & Factor loading & $h^{2}$ & $\kappa$ & Variance \\
\hline \multirow[t]{12}{*}{ Fear of Childbirth Process } & $\begin{array}{l}\text { 25. I am afraid that my spouse's health will be endangered } \\
\text { due to childbirth. }\end{array}$ & 0.868 & 0.822 & \multirow[t]{12}{*}{5.213} & \multirow[t]{12}{*}{$\% 28.96$} \\
\hline & 9. During my spouse's childbirth, I will feel fear. & 0.751 & 0.643 & & \\
\hline & $\begin{array}{l}\text { 6. I am afraid that dangerous medical interventions will be needed } \\
\text { during childbirth. }\end{array}$ & 0.748 & 0.561 & & \\
\hline & 4. As the time of childbirth approaches, my worries increase. & 0.736 & 0.419 & & \\
\hline & 22. I'm afraid that my spouse's childbirth will be risky. & 0.706 & 0.609 & & \\
\hline & 8. During my spouse's childbirth, I will feel helpless. & 0.685 & 0.333 & & \\
\hline & 10. During my spouse's childbirth, I will feel restless. & 0.673 & 0.512 & & \\
\hline & $\begin{array}{l}\text { 26. I am afraid that my child's health will be endangered due to } \\
\text { childbirth. }\end{array}$ & 0.591 & 0.734 & & \\
\hline & 3. I worry about the quality of sex with my spouse after childbirth. & 0.533 & 0.272 & & \\
\hline & 24. I will feel fear because of my spouse's pain. & 0.523 & 0.660 & & \\
\hline & 15. Because of my spouse's fear of childbirth, I feel fear. & 0.482 & 0.525 & & \\
\hline & $\begin{array}{l}\text { 17. I am afraid that I am not capable enough to support my spouse } \\
\text { during childbirth. }\end{array}$ & 0.489 & 0.595 & & \\
\hline \multirow[t]{6}{*}{ Fear of Hospital } & $\begin{array}{l}\text { 31. I am afraid that the hospital staff will not have enough skills to } \\
\text { perform a safe childbirth. }\end{array}$ & 0.997 & 0.883 & \multirow[t]{6}{*}{3.936} & \multirow[t]{6}{*}{$\% 21.86$} \\
\hline & $\begin{array}{l}\text { 32. I am afraid that the hospital will not have enough facilities and } \\
\text { equipment for a safe childbirth. }\end{array}$ & 0.947 & 0.784 & & \\
\hline & $\begin{array}{l}\text { 28. I am afraid that the hospital staff will not take enough care of } \\
\text { my spouse. }\end{array}$ & 0.843 & 0.858 & & \\
\hline & $\begin{array}{l}\text { 29. I'm afraid the hospital staff won't treat me and my spouse } \\
\text { respectfully. }\end{array}$ & 0.762 & 0.879 & & \\
\hline & $\begin{array}{l}\text { 30. I am afraid that my child will be hospitalized in the neonatal } \\
\text { intensive care unit after birth. }\end{array}$ & 0.622 & 0.672 & & \\
\hline & 27. It will be difficult for me to pay for the hospital. & 0.609 & 0.289 & & \\
\hline
\end{tabular}


Table 2 Fit indices of the first- and second-order confirmatory factor analysis of the FFCS

\begin{tabular}{|c|c|c|c|c|c|c|c|c|c|c|}
\hline CFA Index & IFI & CFI & AGFI & PNFI & PCFI & RMSEA & CMIN/DF & $P$-Value & df & $x^{2}$ \\
\hline First-order after construct modification & 0.919 & 0.918 & 0.824 & 0.707 & 0.742 & 0.083 & 2.615 & $<0.001$ & 110 & 287.670 \\
\hline Second-order after construct modification & 0.925 & 0.924 & 0.834 & 0.706 & 0.740 & 0.081 & 2.507 & $<0.001$ & 109 & 273.210 \\
\hline
\end{tabular}

CFA Confirmatory Factor Analysis, CMIN/DF Chi-square/degree-of-freedom ratio, RMSEA Root Mean Square Error of Approximation, PCFI Parsimonious Comparative Fit Index, PNFI Parsimonious Normed Fit Index, AGFI Adjusted Goodness-of-Fit Index, IFI Incremental Fit Index, CFI Comparative Fit Index. Fit indices: PNFI, PCFI, AGFI (>.5), CFI, IFI (>.9), RMSEA (<0.08), CMIN/DF (<3 good, < 5 acceptable)

\section{Scoring}

The 17 items of the FFCS were scored on a five-point Likert scale (I don't agree at all (1), I don't agree ${ }_{(2)}$, I don't have an opinion (3), I agree (4), I completely agree (5)). Therefore, the total score of the scale ranged from 17 to 85 (17-35 low, $36-54$ moderate, $55 \leq$ high). In this way, the more score indicates the more fear of child birth in the expectant fathers.

\section{Discussion}

The purpose of this study was to design and evaluate the psychometric properties of FFCS. The final FFCS, which showed desirable validity and reliability, included 17 items and two factors consisting of fear of childbirth process (12 items) and fear of hospital (5 items), which explained $50.82 \%$ of the total variance. In reliability evaluation, the FFCS showed acceptable internal consistency. The reliability of the total FFCS was established with a Cronbach's alpha of 0.84 , and also the omega was excellent and acceptable.

In this study, the most common indicators of model fitness were evaluated, and all the factor loadings above 0.5 were indicative of a minimum acceptable factor loading. Therefore, based on confirmatory factor analysis, all the fitness indicators had a suitable standard level and the model fitness was appropriate.

The first-order CFA showed that a latent layer was existent, so the secondary-order CFA was used and confirmed the FFCS with two subscales and 17 items. The two subscales represent a more general concept called tocophobia. Tocophobia is comprised of the words "tocos" (a Greek word meaning childbirth) and "phobia" [30]. Tocophobia is considered by its proponents to be a "non-logical fear of childbirth" [31]. The word

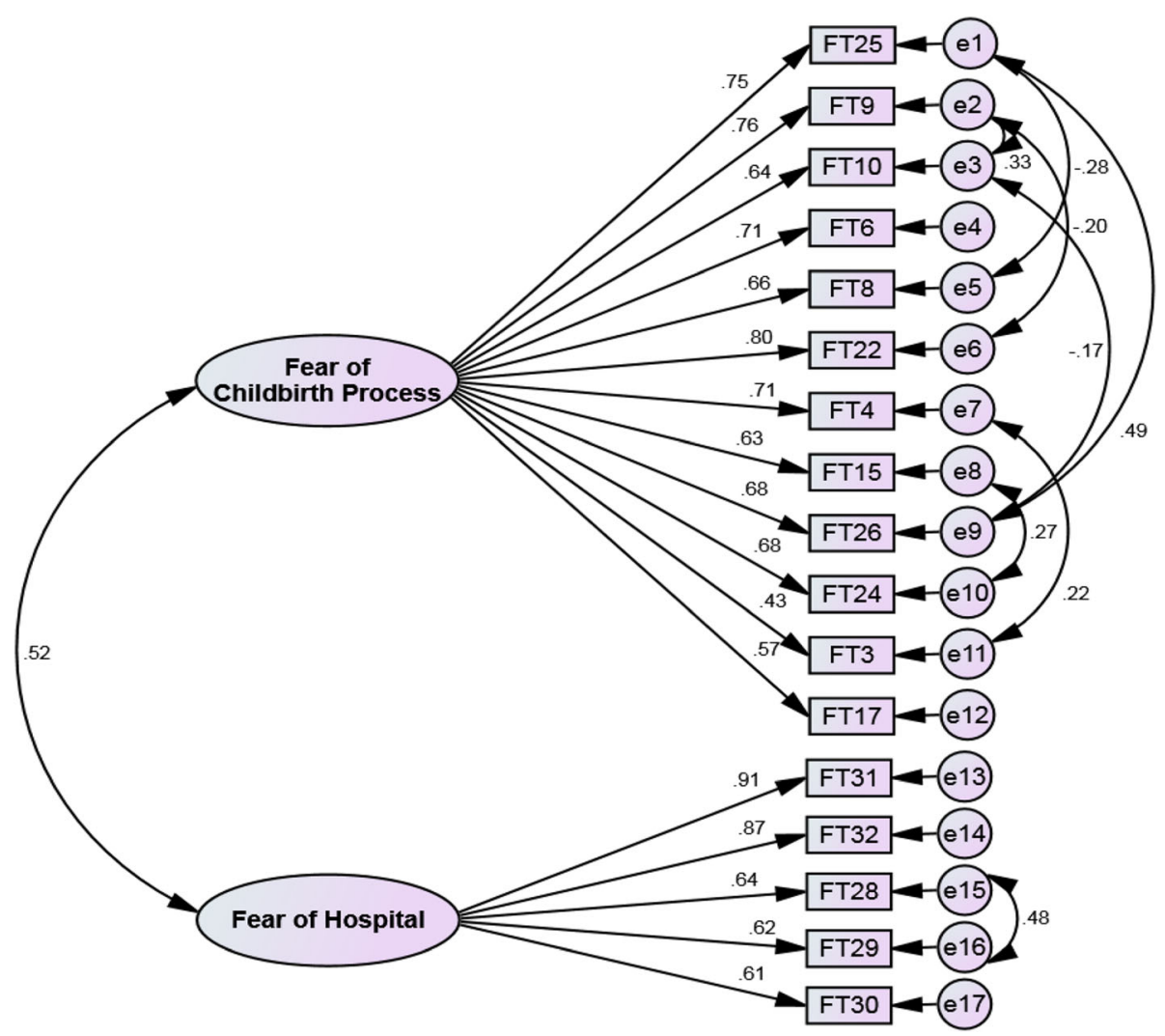

Fig. 2 FFCS construct: modified model of first-order confirmation factor analysis 


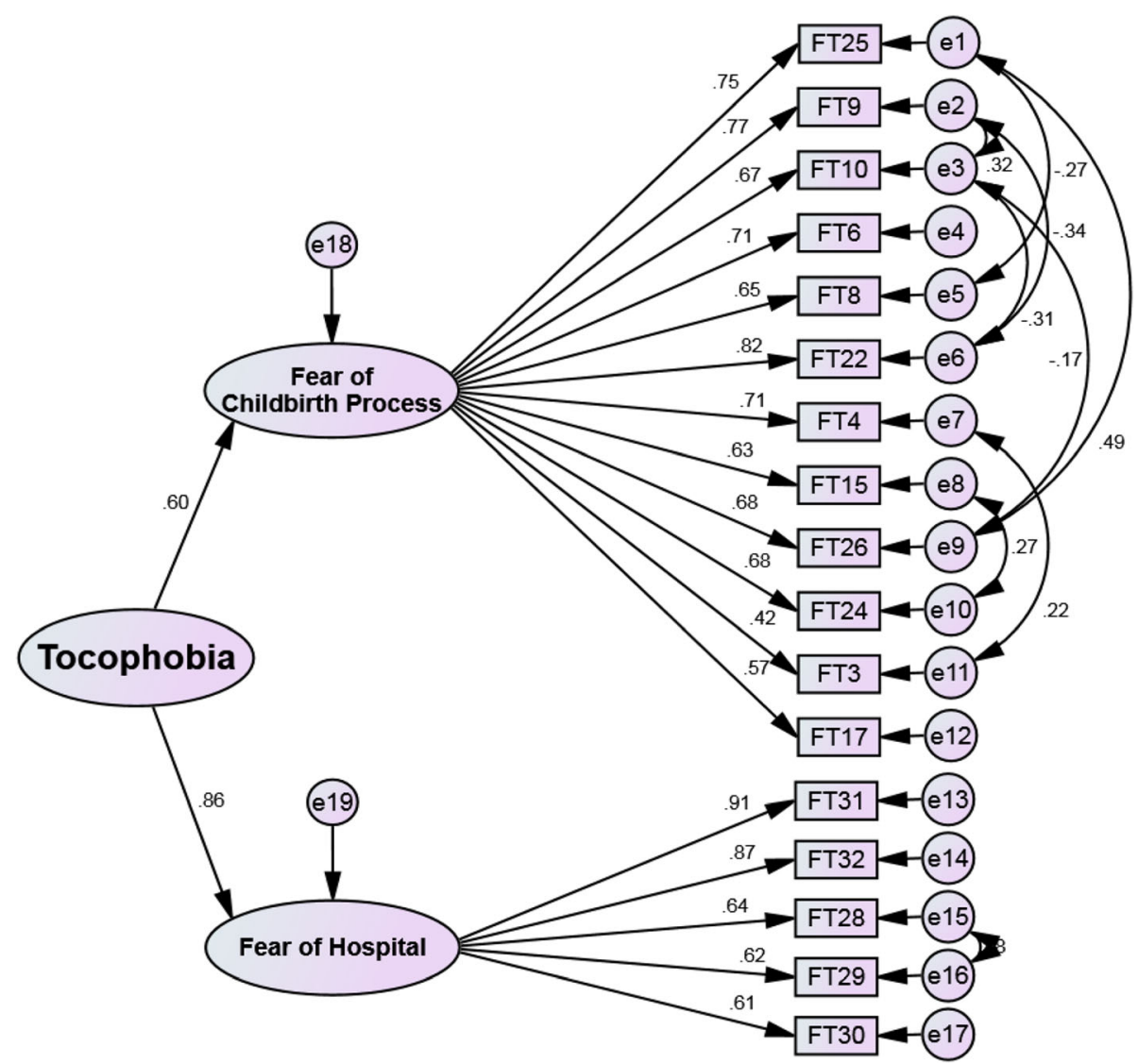

Fig. 3 FFCS construct: modified model of second-order confirmation factor analysis

"tocophobia" as a medical condition was first used by Hofberg and Brockington in 2000 [32]. Tocophobia is divided into two types. Primary tocophobia, which is the destructive fear of childbirth in the first pregnancy, and secondary tocophobia, which, unlike primary tocophobia, is related to the experience of traumatic childbirth in the past [33]. There is little research on men's experience of tocophobia. Published evidence from India showed that most $(78.40 \%)$ first-time expectant fathers suffered from tocophobia to various degrees primarily due to concern for the health and life of their partner and child, labor and delivery process, professional competency, hospital staff behaviors, insufficient medical treatment, fear of not being treated with respect and dignity, fear of partners' and own capabilities, fear of

Table 3 Reliability indices of FFCS

\begin{tabular}{llll}
\hline Index & Alpha $(\mathbf{9 5 \%} \mathrm{Cl})$ & AIC & Omega \\
\hline Factor & & & \\
Fear of Childbirth Process & $0.908(0.889-0.924)$ & 0.449 & 0.909 \\
Fear of Hospital & $0.861(0.830-0.887)$ & 0.554 & 0.865 \\
\hline
\end{tabular}

Alpha Cronbach's alpha, CI Confidence Interval, AIC Average Inter-Item Correlation, Omega McDonald's omega coefficient exclusion from decision making, financial matters, and fear of parenting role [34].

The first subscale identified in the exploratory factor analysis was fear of childbirth process. This subscale explained a higher amount of variance than the other subscales. Among the labor-associated fears reported by fathers were seeing the spouse in pain and agony [35], harm to fetus during delivery, being in an unfamiliar situation [36], episiotomy, risk of maternal complications and death associated with cesarean section [6,37], irreversible rupture [5], prolonged labor [38, 39], and concern for the child's welfare [40]. Fathers also expressed distress regarding their ability to provide appropriate support to their spouse during labor and childbirth and to react properly to labor-related events [7]. In line with this finding, other research examining the fear of childbirth in fathers has shown that the major fears were related to the health and life of the baby and spouse and the labor and delivery process [5].

Fear of hospital was the second subscale of the FFCS. Hospital may be a very distressing environment for many individuals and this may promote fear in fathers [6]. These findings suggest that some of the risk factors 
for fear of childbirth were associated with the health care system [5]. In fact, health care providers have been identified as both a cause of fear and a key factor in reducing the fear of childbirth.

A few numbers of instruments have been used to investigate the fear of childbirth in fathers. Among them, the data from this paper indicates that the FFCS may be a better instrument for measuring fear of childbirth in fathers. Although the validity and reliability of Ringler's questionnaire were confirmed, this questionnaire includes 52 items, which is arguably too time-consuming for fathers to fill out [16]. The W-DEQ is another instrument used for the same purpose, which has two versions for assessing childbirth fear during pregnancy (version A) and after childbirth (version B) [17, 41]. The scales were designed to measure different dimensions of fear of childbirth, though it was ideated as a onedimensional instrument. Wijma et al. estimated the reliability of the questionnaire by split half and Cronbach's alpha to be 0.89 and 0.93 , respectively [17]. Among the most recent questionnaires on fear of childbirth is the FOBS, which comes in two forms, a single item and a new version with two items $[19,20]$. In the new version, the two items measuring fear and worry were strongly correlated $(r=0.83)$. The inclusion of two items allows an estimate of the scale's reliability (using Cronbach's alpha), something that is not possible for single-item ratings $[19,42]$. In the new version, the Cronbach's alpha value was 0.91 , indicating that the scale has very high internal consistency. Mann-Whitney $U$ test revealed no statistically significant difference between the FOBS scores obtained from the single-item (median $=38$, mean $=41.00, \mathrm{SD}=21)$ and the two items (median $=37$, mean $=38.20, S D=24.10)$ versions [19]. However, despite the use of these instruments among fathers, there is no accurate data showing that the cut-off score set for the statistical population of pregnant women is also indicative of fear in men [12].

\section{Implications}

According to a statement from the International Conference on Population and Development (ICPD) on men's participation and responsibility, gender justice should be targeted at all levels of life, including family and social life, and men should be encouraged and empowered to take responsibility for their reproductive and sexual behaviors and their family and social roles. Therefore, today, the role and participation of fathers is emphasized in various aspects of reproductive health, including the childbirth process [43].

On the other hand, the rate of cesarean delivery is ever increasing, and one of the reasons is the growing tendency towards elective cesarean. Studies show that the fear of childbirth in fathers has affected the spike in the rate of cesarean delivery [13]. However, very few studies addressing the fear of childbirth in fathers have been conducted $[15,18]$. One of the main reasons for limited studies in this field is the lack of appropriate instruments for use among fathers. Therefore, introducing this instrument may pave the way for further studies on this issue. A valid and reliable scale could be a good starting point for practitioners to engage with fathers. Having a formal scale that could identify areas of concern would enable health care practitioners to address those areas with individual fathers and also systematically within their service.

\section{Strengths and limitations}

The available scales on fear of childbirth are tools targeting the pregnant mothers. The greatest strength of this study is that it developed a specific tool for assessing fear of childbirth in expectant fathers. The other strength of this instrument lies in its development based on empirical data and the existing literature and its construct validity assessment via both exploratory and confirmatory factor analyses. One of our limitations is that this tool was developed in an eastern culture, where fathers may be reluctant to express fear and it was difficult for them to talk about their fears. As a multitude of factors can contribute to the fear of childbirth, psychometric evaluation of this instrument is recommended in different cultural and clinical contexts. Furthermore, the use of a newly designed questionnaire need further psychometric testing at a national level to ensure the robustness of the measure.

\section{Conclusions}

FFCS (Supplementary file 1) is a simple report instrument with proper validity and reliability for the assessment of fear of childbirth in fathers. It can be easily implemented by researchers, midwives, obstetricians and health care providers. This tool allows for designing interventions and studies that may result in turning labor and delivery into a positive experience for fathers in future.

\footnotetext{
Abbreviations

FFCS: Father's Fear of Childbirth; W-DEQ: Wijma Delivery Expectancy/ Experience Questionnaire; AIC: Average Inter-Item Correlation; CVR: Content validity ratio; CVI: Content validity index; I-CVI: Item CVI; S-CVI/Ave: Average scale-level CVI; EFA: Exploratory Factor Analysis; CFA: Confirmatory Factor Analysis; IFI: Incremental Fit Index; CFI: Comparative Fit Index; AGFl: Adjusted Goodness of Fit Index; PNFI: Parsimony Normed Fit Index; PCFI: Parsimony Comparative Fit Index; RMSEA: Root Mean Score Error of Approximation; CMIN/DF: Minimum discrepancy function divided by Degrees of Freedom; FOBS: Fear of Birth Scale; SD: Standard Deviation; ICPD: International Conference on Population and Development
} 


\section{Supplementary Information}

The online version contains supplementary material available at https://doi. org/10.1186/s12884-021-03696-7.

\section{Additional file 1.}

\section{Acknowledgments}

Not applicable.

\section{Authors' contributions}

Z.S, H.SN, F. E, SF. G contributed to the design of the manuscript. H.SN and F. E contributed to the implementation and analysis plan. Z. M contributed in data collection. Z. S and SF. G have written the first draft of this manuscript. All authors read and approved the final manuscript.

\section{Funding}

This project was fully supported and funded by MAZUMS, Iran (Grant number: 6677). Funding source has not any role in the design of the study and collection, analysis and interpretation of data.

\section{Availability of data and materials}

The datasets used and analyzed during the current study are available from the corresponding author on reasonable request.

\section{Declarations}

Ethics approval and consent to participate

The Ethics Committee of MAZUMS- Iran approved this study (Code: IR. MAZUMS. REC. 1398.6677). Prior to participation in the study, the objectives of the study were explained to the participants, who were assured that their data would remain confidential. Written informed consents were then obtained from them in line with the Declaration of Helsinki.

\section{Consent for publication}

Not applicable

\section{Competing interests}

The authors have no conflicts of interest relevant to this article.

\section{Author details}

${ }^{1}$ Mazandaran University of Medical Sciences, Sari, Iran. ${ }^{2}$ Amol Faculty of Nursing, Mazandaran University of Medical Sciences, Sari, Iran. ${ }^{3}$ Psychiatry and Behavioral Sciences Research Center, Sexual and Reproductive Health Research Center, Addiction Institute, Mazandaran University of Medical Sciences, Sari, Iran. ${ }^{4}$ Sexual and Reproductive Health Research Center, Mazandaran University of Medical Sciences, Sari, Iran.

\section{Received: 26 August 2020 Accepted: 4 March 2021}

\section{Published online: 20 March 2021}

\section{References}

1. Meleis Al, Sawyer LM, Im E-O, Messias DKH, Schumacher KJAins. Experiencing transitions: an emerging middle-range theory. Ans Adv Nurs Sci 2000;23(1):12-28. doi: https://doi.org/10.1097/00012272-2 00009000-00006.

2. Mercer RT, Ferketich SL, De Joseph J, May KA, Sollid D. Effect of stress on family functioning during pregnancy. Nurse Res. 1988;37:268-75 PMID: 3419943.

3. Schumacher M, Zubaran C, White GJ. Bringing birth-related paternal depression to the fore. Women Birth. 2008;21(2):65-70. https://doi.org/10.1 016/j.wombi.2008.03.008

4. Erkaya R, Karabulutlu Ö, Çalık KYJP-S, Sciences B. Defining childbirth fear and anxiety levels in pregnant women. Procedia Soc Behav Sci. 2017;237:1045-52 https:/doi.org/10.1016/j.sbspro.2017.02.151

5. Eriksson C, Westman G, Hamberg K. Content of childbirth-related fear in Swedish women and men-analysis of an open-ended question. J Midwifery Womens. 2006;51(2):112-8. https://doi.org/10.1016/j.jmwh.2 005.08.010.
6. Hanson S, Hunter LP, Bormann JR, Sobo EJ. Paternal fears of childbirth: a literature review. J Prenatal Educ. 2009;18(4):12-20. https://doi.org/10.1624/1 $05812409 \times 474672$

7. Gree J, Lazenbatt A, Dunne L. 'Fear of childbirth' and ways of coping for pregnant women and their partners during the birthing process: a salutogenic analysis. Evid Based Midwifery. 2014;12(3):95-100.

8. Eriksson C, Salander P, Hamberg K. Men's experiences of intense fear related to childbirth investigated in a Swedish qualitative study. Midwifery. 2007; 4(4):409-18. https://doi.org/10.1016/j.midw.2005.10.002.

9. Larsson B. Treatment for childbirth fear with a focus on midwife-led counselling: a national overview, women's birth preferences and experiences of counselling: Acta Universitatis Upsaliensis; 2017. http:// urn.kb.se/resolve?urn=urn:nbn:se:uu:diva-326007. Available January 2021

10. Beardshaw T. Supporting the role of fathers around the time of birth. MIDI RS Midwifery Digest. 2001;11(4):474-7.

11. Barclay L, Donovan J, Genovese A. Men's experiences during their partner's first pregnancy: a grounded theory analysis. Aust J Adv Nurs. 1996;13(3):1224 PMID: 8717683

12. Hildingsson I, Johansson M, Fenwick J, Haines H, Rubertsson C. Childbirth fear in expectant fathers: findings from a regional Swedish cohort study. Midwifery. 2014;30(2):242-7. https://doi.org/10.1016/j.midw.2013.01.001.

13. Fenwick J, Gamble J. Hauck YJJoan. Reframing birth: a consequence of cesarean section. J Adv Nurs. 2006;56(2):121-30. https://doi.org/10.1111/j.13 65-2648.2006.03991_1.x

14. Eriksson C, Westman G, Hamberg K. Experiential factors associated with childbirth-related fear in Swedish women and men: a population based study. J Psychosom Obstet Gynaecol. 2005;26(1):63-72. https://doi.org/10.1 080/01674820400023275

15. Bergström M, Rudman A, Waldenström U, Kieler H. Fear of childbirth in expectant fathers, subsequent childbirth experience and impact of antenatal education: subanalysis of results from a randomized controlled trial. Acta Obstet Gynecol Scand. 2013;92(8):967-73. https://doi.org/1 0.1111 /aogs.12147.

16. Ringler M. The fear of childbirth in expectant fathers. Psychosom Obstet Gynecol 1983:2:161-9.

17. Wijma K, Wijma B, Zar M. Psychometric aspects of the W-DEQ; a new questionnaire for the measurement of fear of childbirth.J Psychosom Obstet Gynaecol. 1998;19(2):84-97. https://doi.org/10.3109/01674829809048501.

18. Bergström $M$, Kieler $H$, Waldenström U. Gynaecology. Effects of natural childbirth preparation versus standard antenatal education on epidural rates, experience of childbirth and parental stress in mothers and fathers: a randomised controlled multicentre trial. BJOG. 2009:116(9):1167-76. https:// doi.org/10.1111/j.1471-0528.2009.02144.x.

19. Haines H, Pallant JF, Karlström A, Hildingsson I. Cross-cultural comparison of levels of childbirth-related fear in an Australian and Swedish sample. Midwifery. 2011:27(4):560-7. https://doi.org/10.1016/j.midw.2010.05.004

20. Rouhe H, Salmela-Aro K, Halmesmäki E, Saisto T. Fear of childbirth according to parity, gestational age, and obstetric history. BJOG. 2009:116(1):67-73. https://doi.org/10.1111/j.1471-0528.2008.02002.x

21. Rademakers J, Waverijn G, Rijken M, Osborne R, Heijmans M. Towards a comprehensive, person-centred assessment of health literacy: translation, cultural adaptation and psychometric test of the Dutch Health Literacy Questionnaire. BMC Public Health. 2020;20:1850. https://doi.org/10.1186/s12 889-020-09963-0.

22. Graneheim UH, Lundman B. Qualitative content analysis in nursing research: concepts, procedures and measures to achieve trustworthiness. Nurs Educ Today. 2004;24(2):105-12. https://doi.org/10.1 016/j.nedt.2003.10.001

23. Guba EG, Lincoln YS. Competing paradigms in qualitative research. In: Denzin NK, Lincoln YS, editors. Handbook of qualitative research. London: Sage Publications, Inc; 1994. p. 105-17.

24. Polit DF, Beck CT. Essentials of nursing research: appraising evidence for nursing practice. Philadelphia: Lippincott Williams \& Wilkins; 2009.

25. Lawshe $\mathrm{CH}$. A quantitative approach to content validity. Perssonel Psychol. 1975;28(4):563-75. https://doi.org/10.1111/j.1744-6570.1975.tb01393.x.

26. MacCallum RC, Widaman KF, Zhang S, Hong S. Sample size in factor analysis. Psychol Methods. 1999:4(1):84. https://doi.org/10.1037/1082989X.4.1.84.

27. Munro BH. Statistical methods for health care research. Philadelphia: Lippincott Williams \& Wilkins; 2005. 
28. Samitsch C. Data quality and its impacts on decision-making: how managers can benefit from good data: Springer; 2014. https://doi.org/10.1 007/978-3-658-08200-0.

29. Javali SB, Gudaganavar NV, Raj SM. Effect of varying sample size in estimation of coefficients of internal consistency. Webmed Central Biostat. 2011;2(2):WMC001649.

30. Striebich S, Mattern E, Ayerle GM. Support for pregnant women identified with fear of childbirth (FOC)/tokophobia-a systematic review of approaches and interventions. Midwifery. 2018;61:97-115. https://doi.org/10.1016/j. midw.2018.02.013.

31. Lee E. Medicalizing motherhood. Society. 2006;43(6):47-50. https://doi.org/1 0.1007/BF02698485.

32. Scollato A, Lampasona R. Tokophobia: When fear of childbirth prevails. Mediterran J Clin Psychol. 2013;1(1). https://doi.org/10.6092/2282-1619/2 013.1.893.

33. Hofberg K, Brockington I. Tokophobia: an unreasoning dread of childbirth: a series of 26 cases. Br J Psychiatry. 2000;176(1):83-5. https://doi.org/10.1192/ bjp.176.1.83

34. Ganapathy T. Tokophobia among first time expectant fathers. Int J Psychiat Nurs. 2015;1(1):99-106. https://doi.org/10.5958/2395-180X.2015.00024.9.

35. Wöckel A, Schfer E, Beggel A, Abou-Dakn M. Getting ready for birth: impending fatherhood. BJM. 2007;15(6):344-8. https://doi.org/10.12968/ bjom.2007.15.6.23673.

36. Szeverenyi P, Poka R, Hetey M, Török Z. Contents of childbirth-related fear among couples wishing the partner's presence at delivery. J Psychosom Obstet Gynecol. 1998;19(1):38-43. https://doi.org/10.3109/0167482 9809044219

37. Chalmers B, Meyer D. What men say about pregnancy, birth and parenthood. J Psychosom Obstet Gynecol. 1996;17(1):47-52. https://doi. org/10.3109/01674829609025663.

38. Dellmann T. The best moment of my life: a literature review of fathers experience of childbirth. Aust Midwifery. 2004;17(3):20-6. https://doi.org/1 0.1016/S1448-8272(04)80014-2.

39. Hunter L, Bormann J, Belding W, Sobo EJ, Axman L, Reseter BK, et al Satisfaction and use of a spiritually based mantram intervention for childbirth-related fears in couples. Appl Nurs Educ. 2011;24(3):138-46. https://doi.org/10.1016/j.apnr.2009.06.002.

40. Vehviläinen-Julkunen K, Liukkonen AJ. Fathers' experiences of childbirth. Aust Midwifery. 1998;14(1):10-7. https://doi.org/10.1016/S0266-6138(98)90109-7.

41. Mortazavi FJ. Validity and reliability of the Farsi version of Wijma delivery expectancy questionnaire: an exploratory and confirmatory factor analysis. Electron Physician. 2017;9(6):4606. https://doi.org/10.19082/4606.

42. Streiner DL, Norman GR, Cairney J. Health measurement scales: A guide to their development and use. 5th ed: Oxford University Press; 2015. https:// doi.org/10.1093/med/9780199685219.001.0001

43. Jamali F, Olfati F, Oveisi S, Ranjkesh F. Effects of spouses' involvement in pregnancy on fear of childbirth in nulliparous women. J Inflamm Dis. 2018; 22(2):38-47. https://doi.org/10.29252/qums.22.2.38.

\section{Publisher's Note}

Springer Nature remains neutral with regard to jurisdictional claims in published maps and institutional affiliations.

Ready to submit your research? Choose BMC and benefit from:

- fast, convenient online submission

- thorough peer review by experienced researchers in your field

- rapid publication on acceptance

- support for research data, including large and complex data types

- gold Open Access which fosters wider collaboration and increased citations

- maximum visibility for your research: over $100 \mathrm{M}$ website views per year

At BMC, research is always in progress.

Learn more biomedcentral.com/submissions 